\title{
Current surgical treatment of nonsmall cell lung cancer 2001
}

\author{
J. Deslauriers
}

\begin{abstract}
Current surgical treatment of nonsmall cell lung cancer 2001. J. Deslauriers. (C)ERS Journals Ltd 2002.

ABSTRACT: Recognizing that surgical treatment is still the best option for controlling lung cancer, surgeons want an operation to be performed when the benefits clearly outweigh the possible risks, and when it has been determined that cancer resection is the most appropriate course of management. The necessity for a compulsive attitude toward preoperative assessment is therefore to be emphasized.

Approximately $45 \%$ of all lung cancers are limited to the chest, where surgical resection is the most effective method of controlling the disease. Patients with tumour (T) 1 , node (N) 0 and T2NO tumours have early lung cancer, and most are curable by resection, with 5-yr survival rates in the range $75-80 \%$ for patients with T1NO status. The "gold standard" of surgery remains lobectomy. Stage T1N1 and T2N1 carcinomas represent a group of patients in whom the disease involves hilar and bronchopulmonary nodes. This group is best treated by complete resection and mediastinal lymphadenectomy.

Survival data following surgical resection of T3 tumours clearly show better survival in patients with T3N0 disease than in those with T3N1-2 disease. Five-year survival rates for completely resected T3N0 lesions are in the range 30-50\%. Once N1 disease is present, survival decreases to $15-20 \%$. Incomplete resections fail to cure and surgery is not indicated if $\mathrm{N} 2$ disease is documented preoperatively. On occasion, T4 tumours involving the carina or vertebral body can be completely resected but T4N1-2 lesions are virtually incurable by surgery.

The presence of mediastinal lymph node metastasis ( $\mathrm{N} 2 / \mathrm{N} 3$ disease) is an ominous prognostic sign and stage III-b disease, by virtue of metastatic contralateral nodes, is an absolute contraindication to surgical resection. Induction treatments with chemoradiation have shown prolongation of survival and three randomized trials have demonstrated a survival advantage over surgery alone.

Eur Respir J 2002; 19: Suppl. 35, 61s-70s.
\end{abstract}

\author{
Correspondence: J. Deslaurier \\ Centre de pneumologie de \\ 1'Hôpital Laval \\ 2725 chemin Sainte-Foy \\ Sainte-Foy QC \\ G1V 4G5 \\ Canada \\ Keywords: Lung cancer \\ resectability \\ surgery \\ survival
}

Received: August 102001

Accepted August 132001
Lung cancer is a significant health problem, with $\sim 170,000$ new cases being diagnosed annually in the USA. Of these, $\sim 45 \%$ are limited to the thorax, where surgery is the most effective method of controlling the disease. Recognizing this concept, surgeons want an operation to be performed when the benefits clearly outweigh the possible risks, and when it has been determined that cancer resection is the most appropriate course of management.

The necessity for a compulsive attitude towards preoperative assessment is therefore to be emphasized since rational treatment and prognosis depend largely on the stage of the disease at the time of diagnosis. In the preoperative setting, the techniques used should be sequential and logical and help to identify patients suitable for treatment with curative intent. They should define the patients most likely to benefit from pulmonary resection while ensuring that no individual is denied the chance of curative resection based on radiological or clinical findings alone [1]. They should also help in the selection of patients eligible for induction therapy programmes. If proper pretreatment staging is accomplished, the rate of exploratory thoracotomy or incomplete resection should not exceed $8-10 \%$. Ultimately, the prognosis of the resected patient with lung cancer is based on complete intraoperative staging, which can be performed by either systematic node sampling or complete lymphadenectomy. At present, neither of these techniques has been shown to improve survival.

Patients with tumour (T) 1 , node $(\mathrm{N}) 0$ and T2N0 tumours have early lung cancers, and most are curable by resection, with 5-yr survival rates in the range $75-80 \%$ for patients with T1N0 status. Stage T1N1 and T2N1 carcinomas represent a group of patients in whom the disease involves hilar and bronchopulmonary nodes. This group is best treated by complete resection and mediastinal lymphadenectomy. Survival data following surgical resection of higher stage primary tumours clearly show better survival in patients with N0 disease than in patients with nodal metastasis.

The presence of $\mathrm{N} 2$ disease is an ominous prognostic factor, although induction therapies involving chemotherapy or chemoradiation appear to prolong survival versus surgery alone in the group of patients that is amenable to complete resection.

This review summarizes the survival information available for the various subsets of nonsmall cell lung cancer (NSCLC). It is acknowledged that nearly all of 
these data come from surgical series in which resection of the primary tumour was the mainstay of treatment.

\section{Clinical and surgical staging of nonsmall cell lung cancer}

The Union Internationale Contre le Cancer and American Joint Committee on Cancer Staging have recently established new criteria for tumour, node, metastasis (TNM) staging of lung cancer, and the prognosis for the various TNM subsets has also been redefined (table 1) [2].

In this revised TNM classification, the descriptors have generally remained the same as those described in 1986 [3]. Tumours classified as T3 are neoplasms that have grown beyond the lung parenchyma to involve structures still amenable to resection, whereas T4 defines those tumours with extensive extrapulmonary extension, usually precluding curative or complete resection. The $\mathrm{T} 4$ descriptor also includes tumours with satellite nodules located within the same lobe. Satellite nodules located in the ipsilateral nonprimary tumour lobe(s) of the lung are designated M1.

The classification of regional lymph node stations has been addressed by MountaIn and Dressler [4], who tried to combine the features of the two systems that have been in use for $>30 \mathrm{yrs}$, the first one based on the work of T. Naruke and advocated by the American Joint Committee on Cancer Staging [5] and the second being the nodal map proposed by the American Thoracic Society [6]. In the proposal of Mountain and Dressler [4], all N2 nodes are contained within the mediastinal pleural envelope and are numbered 1-9. It is understood, although not clearly stated, that, in many cases, the mediastinal pleural reflection is difficult to identify, even on surgery, and so the distinction between hilar nodes (N1) and low tracheobronchial nodes (N2) may be difficult to make. Anatomically, the pleural envelope begins just proximal to the origin of the upper lobe bronchus, and so all lymph nodes cephalad to this point should be designated as mediastinal.

Table 1.-Revised stage grouping of tumour, node, metastasis (TNM) subsets

\begin{tabular}{llcc}
\hline Stage & TNM subset & \multicolumn{2}{c}{ Cumulative 5-yr survival \% } \\
\cline { 3 - 4 } & & cTNM & pTNM \\
\hline I-a & T1N0M0 & 61 & 67 \\
I-b & T2N0M0 & 38 & 57 \\
II-a & T1N1M0 & 34 & 55 \\
II-b & T2N1M0 & 24 & 39 \\
& T3N0M0 & 22 & 38 \\
III-a & T1-3N2M0 & 13 & 23 \\
& T3N1M0 & 9 & 25 \\
III-b & T4N0-2M0 & 7 & \\
& T1-4N3M0 & 3 & \\
IV & Any T, any NM1 & 1 & \\
\hline
\end{tabular}

cTNM: clinical TNM stage; pTNM: pathological TMN stage. (From [2].)

\section{Preoperative diagnosis}

Although some surgeons continue to advocate thoracotomoy without diagnosis because "you are going to operate anyway", adequate treatment planning begins with a proper diagnosis of the underlying disease process [7]. This information allows for a clear discussion with the patient as to what will be done at operation, as well as for streamlining the investigation of the lesion. Further, it avoids reliance on intraoperative frozen section results, which can at times be misleading.

With improved biopsy techniques, often performed under computed tomographic guidance, and with refinements in the pathological interpretation of small specimens, the diagnosis of lung cancer can be made preoperatively in virtually all patients. Flexible bronchoscopy is reliable in central tumours, which represent $30 \%$ of all lung neoplasms, whereas percutaneous fine-needle aspiration biopsy can establish the diagnosis in as many as $90-95 \%$ of peripheral tumours [8]. It is important to understand that a negative result does not exclude malignancy, especially if the cytological findings are reported as unsatisfactory or nonspecific. In these individuals, repeat biopsy may be of value.

\section{Clinical staging of the node factor}

The presence of metastases to regional lymph nodes significantly influences both the treatment and prognosis of patients with NSCLC. The presence of N1 nodes, although rarely of crucial importance except perhaps in patients with T3-T4 tumours, means more extensive resection with increased surgical risk and reduced prospects for cure. At present, the techniques used for preoperative documentation of N1 status are imperfect, and computed tomography (CT) does not appear to be better than chest radiography or oblique tomography, especially in cases where the hilum is of normal size on routine examination. Hilar abnormalities may be easier to detect with magnetic resonance imaging (MRI) because nodes can be more readily distinguished from local blood vessels by this technique.

The presence of mediastinal lymph node metastases (N2, N3 disease) is an ominous prognostic sign. Physical examination can detect enlarged supraclavicular nodes, but this type of examination is notoriously inaccurate if performed by an inexperienced examiner. Careful clinical history taking and physical examination can also detect evidence of superior vena cava obstruction or left recurrent nerve palsy, both being nearly absolute signs of N2 disease.

Advanced invasive and noninvasive techniques are currently used to preoperatively determine the status of mediastinal nodes. Imaging modalities such as CT and MRI can demonstrate nodal enlargement but cannot confirm histological involvement. Conversely, more invasive procedures such as mediastinoscopy, anterior mediastinotomy, video-assisted thoracic surgery (VATS) and, ultimately, thoracotomy are more specific for assessing lymph nodes but require 
operative intervention. At present, the choice of techniques to be used continues to be one of the most controversial issues in the staging of lung cancer.

Invasive procedures used to determine the nodal status involve long tubes being passed through small holes into highly vascular surroundings [9]. Despite this frightening description, these techniques can be carried out with low morbidity if the operator is experienced and familiar with the local anatomy.

As reported by CARLens [10] and PEARson and coworkers [11, 12], mediastinoscopy involves the inspection, palpation and biopsy of superior mediastinal nodes. It is a useful and accurate technique that should be used when nodal involvement as determined by CT is unclear (nodes $>1 \mathrm{~cm}$ in diameter), or when it is required to have an exact knowledge of mediastinal involvement, such as in higher stage (T2-T3) centrally located or undifferentiated tumours. In patients in whom induction treatments are contemplated, mediastinoscopy should be mandatory. Because mediastinoscopy has a greater sensitivity and specificity than CT for the documentation of mediastinal node involvement, some centres still recommend its routine use in all presumably operable lung carcinomas [13].

Lymph nodes located in the aortopulmonary window are not accessible by cervical mediastinoscopy, but biopsy can be performed via left anterior mediastinotomy [14], often referred to as the Chamberlain procedure [15], or through extended standard cervical mediastinoscopy [16]. The information gained from these procedures is particularly important for patients with left upper lobe lesions, in whom survival figures for patients with resectable disease and metastatic subaortic nodes approach those of patients with N1 disease [17].

The role of VATS in accessing mediastinal nodes is unclear, although nodes located in the aortopulmonary window or posterior mediastinum can be readily sampled by this technique. The potential of VATS for disclosing hilar disease may be of importance in patients who cannot tolerate pneumonectomy, or in those in whom N1 disease may need to be documented histologically prior to induction therapy [18].

\section{Surgical therapy for early nonsmall cell lung cancer}

\section{Surgical management of T1NOMO and T2NOMO lung} cancer

The prognosis for surgically treated patients with T1N0M0 NSCLC is generally good, and the 5-yr survival is $\sim 80 \%$. In a series from the Mayo Clinic (Rochester, MN, USA) the survival of 225 patients who had T1N0 lesions was $91 \%$ at 2 yrs and $80 \%$ at 5 yrs [19]. In this series, TNM subset (T1 versus T2), age at operation $(<70$ yrs versus $>70$ yrs), sex (female versus male) and extent of operation (limited resection versus pneumonectomy or lobectomy) were important determinants of survival. There were no differences in survival on the basis of cell type, although the 5 -yr survival rate was slightly better in patients with bronchioloalveolar carcinoma. A number of
Table 2.-Prognostic factors in resected stage I lung cancer

\section{Age}

Sex

$\mathrm{T}$ factor (tumour size)

Visceral pleura invasion

Level of bronchial invasion

Satellite nodules

Histology

Histological differentiation

Blood vessel invasion

DNA ploidy pattern

T: tumour; DNA: deoxyribonucleic acid.

prognostic factors have been identified in resected stage I lung cancer and these are listed in table 2.

Tumour size makes a difference in the survival of patients with T1N0M0 and T2N0M0 lung carcinomas [20-22]. In 1995, MARTINI et al. [20] showed that patients with $\mathrm{T} 1$ lesions did better than those with T2 lesions, and that patients with small tumours $(<1-2 \mathrm{~cm})$ did better than those with tumours of $\geqslant 5 \mathrm{~cm}$. Survival in patients with T1N0 tumours was $82 \%$ at 5 yrs and $74 \%$ at $10 \mathrm{yrs}$, compared with $68 \%$ at 5 yrs and $60 \%$ at 10 yrs for patients with T2 tumours $(\mathrm{p}<0.0004)$. In a group of 221 patients with primary lung cancer, IsHIDA et al. [21] also showed that 5-yr survival rates decreased with larger tumour sizes. This was attributed to an increase in the incidence of occult lymph node metastasis with larger tumours (N1 5\% and $\mathrm{N} 212 \%$ in tumours of $1.1-2.0 \mathrm{~cm}$; N1 $12 \%$ and $\mathrm{N} 225 \%$ in tumours of $2.1-3.0 \mathrm{~cm}$ ) not detected preoperatively or even by intraoperative lymph node sampling.

Visceral pleura involvement does not seem to influence the survival of patients with stage I disease [20], although Ichinose et al. [23] were able to document by univariate analysis of survival curves that pleural involvement was a significant prognostic factor. These investigators observed a survival difference between patients having tumours not extending beyond the elastic layer and not exposed on the pleural surface (P1) and those exposed to the pleural surface (P2). The histological type of the tumour is a fairly consistent determinant of time to recurrence and survival in patients with resected stage I carcinomas [24-26]. In a Lung Cancer Study Group (LCSG) analysis, cancer recurrences were more frequent and recurrence rates were higher in patients with tumours of nonsquamous histology (table 3) [24].

Other LCSG data showed that 5-yr survival following surgery in patients with T1N0 tumours was $83 \%$ for squamous carcinomas and $69 \%$ for

Table 3. - Recurrence of squamous versus nonsquamous tumours

\begin{tabular}{lccc}
\hline $\begin{array}{l}\text { Histological } \\
\text { type }\end{array}$ & $\begin{array}{c}\text { Patients } \\
\mathrm{n}\end{array}$ & $\begin{array}{c}\text { Recurrences } \\
\mathrm{n}\end{array}$ & $\begin{array}{c}\text { Recurrence } \\
\text { rate }\end{array}$ \\
\hline Squamous & 226 & 25 & 0.042 \\
Nonsquamous & 346 & 82 & 0.106 \\
\hline
\end{tabular}

(From [24].) 
Table 4. - Limited resection as a compromise operation

\begin{tabular}{llc}
\hline First author [Ref.] & Patients n & 5-yr survival \% \\
\hline BENNETT [32] & 31 (segmental) & 36 \\
HOFFMAN [33] & 33 (wedge) & 25 \\
KUTSCHERA [24] & 57 & 23 \\
ERRETT [35] & 100 (wedge) & 69 \\
MILLER [36] & 32 & 31 \\
\hline
\end{tabular}

adenocarcinomas $(\mathrm{p}=0.02)$; for patients with $\mathrm{T} 2 \mathrm{~N} 0$ tumours, these rates were $64 \%$ and $57 \%$, respectively $[26,27]$.

Blood vessel invasion has been inconsistently shown to have prognostic significance in early-stage lung cancer, although two studies [28, 29] have provided data supporting the concept that the absence of blood vessel invasion identifies a group of patients with a very low probability of distant metastasis.

\section{Role of limited resection in surgical management of early lung cancer}

The current "gold standard" of surgical treatment of patients with $\mathrm{T} 1 \mathrm{~N} 0$ and $\mathrm{T} 2 \mathrm{~N} 0$ tumours limited to one lobe is an anatomical lobectomy, regardless of the size of the tumour on presentation [30]. Limited resection, which is defined as a procedure that is less than a lobectomy (generally a wide wedge for peripheral tumours or an anatomical segmentectomy), was introduced by JENSIK et al. [31], who suggested that more limited operations could be adequate for early-stage bronchogenic carcinoma. Since then, many authors have adopted this approach as a compromise alternative to lobectomy for high-risk patients with limited function (table 4) [32-36].

Potential advantages of limited resection include less functioning tissue being resected, the possibility of surgical treatment of subsequent primary tumours and less operative mortality. Possible disadvantages include the potential for increased local recurrence and an increased operative morbidity, consisting primarily of prolonged air leaks.

More recently, some centres have advocated lesser resections as appropriate treatment for uncompromised patients with peripheral T1N0 tumours not transgressing a segmental plane (table 5) [37-39].

In 1994, the Rush-Presbyterian-St.Luke's Medical Center group presented the results of a retrospective study on 173 patients who had undergone segmental resection $(n=68)$ or lobectomy $(n=105)$ for stage I NSCLC over an 8-yr period (1980-1988) [40]. Although a survival advantage was noted for patients with tumours of $\geqslant 3 \mathrm{~cm}$ undergoing lobectomy $(\mathrm{p}=0.006)$, no survival advantage was apparent for

Table 5. - Limited resection as an intentional operation

\begin{tabular}{lcc}
\hline First author [Ref.] & Patients n & 5-yr survival \% \\
\hline READ [37] & 113 & 85 \\
PASTORINO [38] & 61 & 55 \\
KODAMA [29] & 63 & 93 \\
\hline
\end{tabular}

patients undergoing lobectomy for tumours of $<2 \mathrm{~cm}$ in diameter $(\mathrm{p}=0.24)$.

In 1995, the LCSG published the results of a prospective randomized trial comparing limited resection (wedge or segmental) to lobectomy for patients with T1N0 NSCLC [41]. In the limited-resection group, there was a three-fold increase in the overall incidence of local recurrences, the greatest increase being seen among patients with adenocarcinoma, and an observed $30 \%$ increase in overall mortality rate $(p=0.08)$ compared to patients undergoing lobectomy. The analysis also showed a significantly higher local recurrence rate after wedge resection versus segmentectomy, presumably because of inadequate margins around the tumour or failure to identify microscopic N1 disease.

The appropriate application of VATS procedures, whether wedge or lobectomy, for the treatment of early-stage NSCLC remains to be clarified [42, 43].

\section{Surgical management of T1N1 and T2N1 lung cancer}

T1N1M0 and T2N1M0 lung cancers include those in which the disease involves bronchopulmonary and hilar nodes but without metastasis to mediastinal nodes. The T1N1M0 subset is infrequent, and the 5 -yr survival rate after complete resection is $55 \%$ [2]. Survival is $\sim 40 \%$ for patients within the T2N1 subset. In a report from the Memorial SloanKettering Cancer Center, 214 patients with resected T1N1 $(n=35)$ and T2N1 $(n=174)$ NSCLC lesions were analysed with respect to survival and prognostic factors [44]. In that series, the best survival rates were observed in patients with tumours of $\leqslant 3 \mathrm{~cm}$ in diameter, and in those with single node involvement. The authors insisted that this group of patients should undergo surgical resection and that complete resection with mediastinal lymphadenectomy is necessary to insure that no nodal metastasis in the mediastinum is overlooked.

Similar to what is observed in T1N0M0 and T2N0M0 subsets, the histological classification of the tumour is a significant prognostic factor. In LCSG data, the 5-yr survival rate following surgery was $75 \%$ for squamous cell carcinoma and $52 \%$ for adenocarcinoma in the $\mathrm{T} 1 \mathrm{~N} 1$ subset $(\mathrm{p}=0.04)$, and $53 \%$ for squamous cell carcinoma and $25 \%$ for adenocarcinoma in the T2N1 subset $(\mathrm{p}=0.01)[26,27]$. Similarly, ICHINOSE et al. [23] have shown in a multivariate analysis that histological classification (squamous versus nonsquamous; $p=0.0359$ ) was a predominant prognostic factor in patients with pT1N1 and T2N1 disease. MARTINI et al. [44], however, failed to demonstrate a difference in survival between patients with squamous cell carcinoma versus adenocarcinoma $(p=0.238)$, although the pattern of recurrence after resection of $\mathrm{T} 1 \mathrm{~N} 1$ or $\mathrm{T} 2 \mathrm{~N} 1$ tumours differed histologically.

The location and number of N1 nodes as a prognostic factors has been investigated by MARTINI et al. [44] and YANO et al. [45]. In the study of MARTINI et al. [44], there was a significant $(\mathrm{p}=0.016)$ difference in survival rates between patients with involvement of 
a single $\mathrm{N} 1$ node $(45 \%$ at $5 \mathrm{yrs})$ versus those with multiple N1 nodes (31\% at 5 yrs). YANO et al. [45] also reported that the survival associated with lobar N1 disease was significantly $(\mathrm{p}=0.014)$ better than that of hilar N1 disease (64.5 versus $39.7 \%$ at $5 \mathrm{yrs}$ ).

The role of adjuvant therapy in these subsets of patients has been addressed by many investigators. In an LCSG trial, 210 patients with complete resection of stage II (T1N1, T2N1) or stage III squamous carcinoma received either surgery plus radiotherapy $(n=102)$ or surgery alone $(n=108)$ [46]. There was no survival benefit from radiotherapy, but a significantly lower rate of local recurrences $(\mathrm{p}<0.001)$.

Although some studies have suggested that chemotherapy administered in the postoperative setting may prolong survival and disease-free interval in patients with stage II disease [47, 48], a recent metaanalysis showed that postoperative chemotherapy with or without radiotherapy only resulted in a slightly reduced risk of death among patients with surgically resected stage II and III-a disease [49, 50]. One of the main problems remains patient compliance with chemotherapy regimens, which, in the postoperative setting, is in the range 50-60\% [47].

There is some evidence that higher-dose vitamin A chemoprevention may reduce the recurrence rate and improve the disease-free interval in patients curatively resected for stage I lung cancer [51].

\section{Surgical management of T3-T4 lung cancer}

Tumours involving the chest wall, including the superior sulcus, the diaphragm, the mediastinal pleura or the pericardium, or endobronchial tumours located within $2 \mathrm{~cm}$ of the carina are all identified as T3 lesions. Five-year survival rates for completely resected T3N0 tumours is in the range $35-40 \%$. However, once N1 disease is present, the 5-yr survival decreases to $15-20 \%$. In one large series, NARUKE et al. [52] reported an overall 5-yr survival of $25.8 \%$ in 327 patients treated by surgical resection. These $5-y r$ survivals were 31.6 and $33.7 \%$ for T3N0 and T3N1 disease, respectively. In general, surgery is not recommended if N2 disease is documented preoperatively. Although, within the T3 categories, prognosis may vary according to tumour location, a most important surgical tenet is that complete resection must be carried out. In a series of 61 patients with surgically treated T3 NSCLC reported by NAKAHASHI et al. [53], the 5-yr survival for patients undergoing complete resection and incomplete resection was 42 and $10 \%$, respectively $(\mathrm{p}<0.01)$. Of importance to the surgeon is the fact that only $20 \%$ of patients with advanced-stage NSCLC are amenable to complete resection [54].

Tumours invading the heart, great vessels, trachea, oesophagus, mediastinum and vertebral body are considered T4 lesions. As a group, these patients have locally advanced and nonresectable disease, although limited success can be achieved after resection of such tumours with no nodal involvement. In the series of NARUKE et al. [52], a 5-yr survival of $8 \%$ was achieved after resection of $198 \mathrm{~T} 4$ lesions. Patients with T4N1-2 lesions are virtually incurable.

\section{T3: chest wall invasion}

T3 tumours that invade the chest wall but have not yet metastasized to lymph nodes have a favourable prognosis and en bloc resection of both chest wall and lung is the procedure of choice for achieving complete removal of such tumours [55]. A preoperative diagnosis of chest wall invasion is important for the planning of surgery and this diagnosis must be suspected when patients present with localized chest pain. Obvious bone destruction as seen on standard chest radiographs is always indicative of chest wall invasion. Although CT is not completely reliable, RАтто et al. [56] have shown that obliteration of the extrapleural fat plane and the ratio of tumour/pleura contact (i.e. percentage of circumference of tumour in contact with pleura) to tumour diameter were important computed tomographic criteria for diagnosing chest wall invasion. The combination of chest wall pain and positive bone scanning nearly always indicates the need for chest wall resection.

The objective of surgery is to completely excise all malignant tissues, but the best means of accomplishing this goal is somewhat controversial. Some authors suggest that all patients with malignant invasion of the parietal pleura should undergo "en bloc" chest wall resection [57], whereas others suggest that "en bloc" resection should only be attempted when there is positive evidence of tumour invasion into the ribs or intercostal muscles [58].

When chest wall resection has to be carried out, it is often limited to segments of two or three ribs and, in most cases, prosthetic reconstruction is not required. Modern operative mortality after "en bloc" resection of lung and chest wall is in the range 3-5\%. Important prognostic factors are completeness of resection, nodal status and depth of invasion $[55,59]$. In one recent series [55], 104 patients underwent complete resection for lung neoplasms involving the chest wall with no operative mortality and an overall 5-yr survival of $61.4 \%$. Survival in the subsets T3N0 and T3N2 were 67.3 and $17.9 \%$, respectively ( $p=0.007)$. The 5 -yr survival was $79.1 \%$ if only the parietal pleura was involved and $54.0 \%$ if soft tissues and/or bone were infiltrated $(p=0.014)$. In another series of completely resected patients, univariate and multivariate analysis identified nodal involvement, depth of parietal invasion and age as independent prognostic factors [59].

The role of adjuvant radiotherapy given either preor postoperatively is still controversial. In the Toronto series [60], an improved survival rate was observed in the irradiated group, whereas, in the Mayo Clinic Report [61] and in the series from France [59], the authors did not note any benefit to survival.

\section{T3: superior sulcus tumours}

Superior sulcus tumour refers to a primary lung cancer that occurs at the apex of the lung and often invades the upper two or three ribs (T3), vertebral bodies (T4), lower part of the bronchial plexus 
(C8-T1, T4) and stellate ganglion [62], causing Pancoast syndrome [63]. The first report of a series of curative resections in such patients was that of SHAw et al. [64] in 1961, and their strategy of preoperative irradiation (30 cGy over 3 weeks) followed by resection utilizing a posterior approach has remained the standard of care until recently. The overall 5-yr survival for patients with N0 disease and completely resected tumours of the superior sulcus is in the range $30-35 \%$ at 5 yrs. In most series, the absence of N2 disease is the most important prognostic factor, with 5-yr survival being as high as 50\% in patients with $\mathrm{T} 3 \mathrm{~N} 0$ lesions. There were only a handful of survivors in the N2 group [65]. This is the main reason why mediastinoscopy should always be performed before treatment is planned. It is also the present author's practice to sample supraclavicular nodes, if they are enlarged, by ultrasonography. Adenocarcinoma, the presence of Horner's syndrome and bony erosion appear to adversely influence prognosis [66].

In order to properly select patients for surgery, the surgeon must have sure knowledge of the tumour's anatomy in the lower neck and thoracic inlet. Although CT is helpful in evaluating vertebral involvement, it is not as accurate as MRI for the assessment of vascular involvement (subclavian artery or vein) or invasion of nerve roots or intervertebral foramina. With modern surgical techniques and a multidisciplinary approach, it is possible to completely resect tumours that locally invade vertebral bodies, the subclavian artery and C8-T1 nerve roots. In a recent publication from the MD Anderson Cancer Center, GANDHI et al. [67] reported on 17 patients who underwent total vertebrectomy $(n=7)$, partial vertebrectomy $(n=7)$ or neural foramina or transverse process resection $(n=3)$ for superior sulcus tumours. There were no perioperative deaths and overall actuarial survival at 2 yrs was $54 \%$. The authors concluded that vertebral body invasion should no longer be considered a contraindication to surgery.

More recently, a cervical approach has been advocated by DARTEVELLE et al. [68] for anteriorly located tumours. This approach (alone or in combination with posterolateral thoracotomy) provides excellent exposure of the subclavian blood vessels and brachial plexus. In 1997, GRUNENWALD and SPAGGIARI [69] described a similar approach but leaving the clavicle/manubrial joint intact in order to improve cosmetic defects and shoulder stability.

The exact role of preoperative radiotherapy as described by SHAw et al. [64] is still controversial because the value of their regimen has never been documented in a randomized trial. Indeed, such a trial would be almost impossible to carry out because resectable superior sulcus tumours are uncommon. Two retrospective studies have, however, demonstrated a significant survival advantage in patients irradiated preoperatively $[65,70]$. More recently, chemotherapy and radiotherapy have been used preoperatively. However, the exact value and appropriate timing of these adjuncts has not yet been established

\section{T3: proximal airway tumours}

Tumours located within $2 \mathrm{~cm}$ of the carina can be resected by sleeve resection, thus avoiding the need for pneumonectomy, which carries a significantly higher rate of operative morbidity and mortality. Bronchoplastic procedures were originally described for cancer patients unable to tolerate pneumonectomy, but are currently considered a better procedure for noncompromised patients because survival is equivalent to or better than that following pneumonectomy for tumours of similar stage [71]. Although lesions of the right upper lobe are the commonest indications for sleeve lobectomy, bronchoplasty is applicable to any lobe and almost any segment in either lung. The use of sleeve resection when the carcinoma has spread to N1-2 nodes is still an area of controversy.

In one recent series, 184 patients who underwent sleeve lobectomy for lung cancer were reported with an operative mortality of $1.6 \%$ (three deaths) [71]. Survival for all patients was $52 \pm 4 \%$ at 5 yrs and $34 \pm 4 \%$ at 10 yrs (mean \pm SD). For patients with N1 disease $(n=68)$, survival rates were $48 \pm 6$ and $27 \pm 6 \%$ at 5 and $10 \mathrm{yrs}$, respectively. In a collective review of 1,915 patients submitted to bronchoplastic procedures over a 12-yr period (1980-1992), TEDDER et al. [72] reported a 30-day operative mortality of 5.5\% (range $0-11 \%$ ) and 5 -yr survival of $40 \%$. Other authors have reported similar favourable outcomes [73, 74].

Involvement of the pulmonary artery may render sleeve resection impossible unless an elliptical resection or a full sleeve resection of the artery is added to the procedure (double sleeve resection). The exact role of these techniques of angioplasty is unclear not only because of an increased operative mortality, at least in early series, but also because few series have reported long-term results [75, 76]. In 1999, RENDINA et al. [77] described 52 patients who had undergone a variety of pulmonary artery reconstructions for lung cancer. There were no operative deaths and 5-yr survival rates were $38.3 \%$ for the entire group, $18.6 \%$ for stages III-a/III-b, and $64.4 \%$ for stages I and II. In 1997, RENDINA et al. [78] stated that "although it is technically demanding, lobectomy associated with bronchovascular reconstruction is feasible, with good immediate and long-term results after induction chemotherapy."

\section{T4: tumours involving the carina}

Most lung cancers involving the carina or lower trachea are so extensive that complete resection is not possible. Indeed this involvement is often secondary to subcarinal nodes (N2) growing through the airway and into the tracheal lumen. On occasion, however, tumours arising in the upper lobe or in the origin of either main bronchus are sufficiently localized to be amenable to complete resection and reconstruction.

Tracheal sleeve pneumonectomy is a demanding operation with a high risk of complications, although these can be reduced through accurate selection of patients, precise technique and optimal postoperative care [79]. The reported operative mortality ranges 
$7.2-29 \%[80,81]$ and the 5 -yr survival rate is $~ 20 \%$ for patients with N0 disease. It is to be noted that sleeve pneumonectomy is generally carried out for tumours located in the right rather than in the left lung.

\section{T4: tumours invading the spine}

Overall, little success has been obtained following resection of NSCLCs invading the vertebral bodies other than for patients with Pancoast tumours [67]. In 1989, DeMeEster et al. [82] described a technique for resection of tumours closely related to the paravertebral fascia adherent to the spine but without destruction of the vertebral body. Since then, other authors have suggested partial or complete vertebrectomy followed by spinal stabilization [83]. No long-term survival data are yet available for those procedures and most surgeons still consider vertebral body invasion to be an absolute contraindication to surgical resection. As previously stated, incomplete resections do not improve survival and their ability to palliate is questionable [66].

\section{Surgical management of N2 lung cancer}

Patients with stage III-a disease based on involvement of ipsilateral mediastinal nodes (N2) usually do very poorly. However, there has been a trend since the early 1980s towards a more aggressive approach to these patients. MARTini et al. [84] were the first to demonstrate prolonged survival in a group of completely resected patients with $\mathrm{N} 2$ disease. The majority of their patients were felt preoperatively to have had N0 or N1 disease (minimal N2) and their survival after complete resection was $43 \%$ at 3 yrs and $29 \%$ at 5 yrs. Survival with obvious N2 disease as seen on standard radiographs (bulky N2) was poor ( $8 \%$ at $3 \mathrm{yrs})$. In some series, surgical resection combined with postoperative radiation therapy resulted in 5-yr survivals of up to $40 \%[85,86]$.

The classic paper of PEARSON et al. [87] showed that patients with N2 disease who underwent complete resection had a much better survival if they had negative mediastinoscopy results (24\%) and $\mathrm{N} 2$ disease was only found on thoracotomy versus patients selected for thoracotomy despite positive mediastinoscopy results (8\%). In a similar analysis, DALY et al. [88] reported the survival of 37 patients who had negative computed tomographic results for metastatic mediastinal nodes but who were found to have cancerous nodes on thoracotomy $(n=36)$, or mediastinoscopy $(\mathrm{n}=1)$. The projected 5 -yr survivals were $31 \%$ for all patients whose tumour could be resected and $45 \%$ for those with peripheral tumours.

Other factors that are considered favourable include the site of $\mathrm{N} 2$ disease (the most favourable being nodes in the aortopulmonary window [86]), the number of nodal stations involved (one versus several) [89], an associated T1-2 primary tumour (versus T3-4) [90], tumour limited to within the node capsule (versus extranodal involvement) and squamous histology [89]. In all reports, the value of radical mediastinal lymph nodes, as described by WATANABE et al. [91], MARTINI et al. [84] and others is emphasized. In the study of WATANABE et al. [91], survival of patients with left-sided N2 disease improved after more aggressive mediastinal node dissections. In another Japanese study, mediastinal lymph node dissection for $\mathrm{N} 2$ disease resulted in better survival compared to resection without nodal dissection [92].

In the early $1980 \mathrm{~s}$, postoperative radiation therapy was also thought to improve survival and was the traditional adjuvant therapy for resected N2 disease [93]. However, a prospective randomized trial of the LCSG found no survival advantage using postoperative radiotherapy in completely resected stage II and III squamous carcinomas despite a clear benefit in controlling local recurrences [94].

Since the mid-1980s, there has been considerable interest in neoadjuvant approaches for patients with N2 disease documented prior to thoracotomy and a large number of phase II trials of induction chemotherapy or chemoradiotherapy have been reported. The rationale for chemotherapy alone is that it potentially allows greater dose intensity as well as the use of some drugs that cannot be administered in conjunction with radiation. In a large study reported by MARTINI et al. [95], the major response rate to cisplatin-based induction chemotherapy was $77 \%$ and the complete resection rate was $65 \%$. All of these trials have shown encouraging prolongation of survival compared with historical series. Perhaps more encouraging is the fact that $10-20 \%$ of resected specimens show no viable tumour. In general, most regimens include high-dose cisplatin with or without radiation.

Recently, the results of two small randomized trials of induction therapy have suggested that induction treatment followed by surgery may be superior to surgery alone [96, 97]. Both of these trials demonstrated a benefit for preoperative chemotherapy with hazard ratios for survival improving five- to sevenfold compared to surgery alone. Unfortunately, the total patient sample size in each trial was small and so the general applicability of these regimens in the day-to-day treatment of patients is still in doubt [98]. In a consensus report, GANDARA et al. [98] write the following about induction chemotherapy: "While preoperative chemotherapy cannot be considered standard of care, it does appear to be a reasonable strategy in minimal stage III-a disease, assuming the multimodality team involved is experienced in this approach and works in a collaborative fashion to maximize efficacy and minimize potential toxicities."

\section{Conclusion}

As can be seen from the present review, the results of surgical resection of lung cancer are still poor except in patients with early-stage tumours, in whom the disease can be cured in up to $70 \%$ of cases. Because of these better survival rates, it is tempting to assume that, with lung cancer screening, tumours will be diagnosed at an earlier stage, and, therefore, overall cure rates will be higher. Unfortunately, prior 
randomized studies carried out in the 1970s have shown that the death rate from lung cancer was not significantly different in patients who were actively screened and those who were not. More recently, techniques of screening by low-dose helical CT and the use of specific biomarkers for lung cancer have shown enough positive results to indicate that screening for lung cancer should perhaps be revisited [99].

Another way of improving the results of therapy in operable lung cancer is in the area of adjuvant treatment. The favourable results obtained after induction treatments in patients with N2 disease may suggest that such modalities should be extended to earlier-stage tumours.

\section{References}

1. Karmy-Jones R, Hyland RH, Lewis JN Jr, Kvale P. Staging lung cancer: current controversies and strategies. Can Respir J 1997; 4: 297-305.

2. Mountain CF. Revisions in the international system for staging lung cancer. Chest 1997; 111: 1710-1717.

3. Mountain CF. A new international staging system for lung cancer. Chest 1986; 89: Suppl. 4, 225s-233s.

4. Mountain CF, Dressler CM. Regional lymph node classification for lung cancer staging. Chest 1997; 111: 1718-1723.

5. American Joint Committee on Lung Cancer. In: Beahrs $\mathrm{OH}$, Hensen DE, Hutter RVP, et al., eds. Manual for Staging of Cancer. 4th Edn. Philadelphia, PA, Lippincott, 1992; pp. 115-121.

6. American Thoracic Society. Clinical staging of primary lung cancer. Am Rev Respir Dis 1983; 127: 1-6.

7. Deslauriers J, Grégoire J. Clinical and surgical staging of non-small cell lung cancer. Chest 2000; 117: 96s$103 \mathrm{~s}$.

8. Weisbrod GL. Transthoracic needle biopsy. World J Surg 1993; 17: 705-711.

9. Johnston MR. Invasive staging of the mediastinum. World J Surg 1993; 17: 700-704.

10. Carlens E. Mediastinoscopy: a method of inspection and palpation in the superior mediastinum. Dis Chest 1959; 36: 343-352.

11. Pearson FG, Nelems JM, Henderson RD, Delarue NC. The role of mediastinoscopy in the selection of treatment for bronchial carcinoma with involvement of superior mediastinal nodes. J Thorac Cardiovasc Surg 1972; 64: 382-390.

12. Pearson FG, Delarue NC, Ilves R, Todd TR, Cooper JD. Significance of positive superior mediastinal nodes identified at mediastinoscopy in patients with resectable cancer of the lung. J Thorac Cardiovasc Surg 1982; 83: 1-11.

13. Coughlin M, Deslauriers J, Beaulieu M, et al. Role of mediastinoscopy in pretreatment staging of patients with primary lung cancer. Ann Thorac Surg 1985; 40: 556-560.

14. Schreinemakers HH, Joosten HJ, Mravunale M, Lacquet LK. Parasternal mediastinoscopy: assessment of operability in left upper lobe lung cancer: a prospective analysis. J Thorac Cardiovasc Surg 1988; 95: 298-302.

15. McNeill TM, Chamberlain JM. Diagnostic anterior mediastinotomy. Ann Thorac Surg 1966; 2: 532-539.

16. Ginsberg RJ, Rice TW, Goldberg M, Waters PF,
Schmocker BJ. Extended cervical mediastinoscopy. A single staging procedure for bronchogenic carcinoma of the left upper lobe. J Thorac Cardiovasc Surg 1987; 94: 673-678.

17. Ginsberg RJ. The role of preoperative staging in left upper lobe tumors. Ann Thorac Surg 1994; 57: 526527.

18. Wain JC. Video-assisted thoracoscopy and the staging of lung cancer. Ann Thorac Surg 1993; 56: 776778 .

19. Williams DE, Pairolero PC, Davis CS, et al. Survival of patients surgically treated for stage I lung cancer. J Thorac Cardiovasc Surg 1981; 82: 70-76.

20. Martini N, Bains MJ, Burt ME, et al. Incidence of local recurrence and second primary tumors in resected stage I lung cancer. $J$ Thorac Cardiovasc Surg 1995; 109: 120-129.

21. Ishida T, Yano T, Maeda K, Kaneko S, Tateishi M, Sugimachi KI. Strategy for lymphadenectomy in lung cancer three centimeters or less in diameter. Ann Thorac Surg 1990; 50: 708-713.

22. Padilla P, Calvo V, Penalver JC, Sales G, Morcillo A. Surgical results and prognostic factors in early nonsmall cell lung cancer. Ann Thorac Surg 1997; 63: 324 326.

23. Ichinose $\mathrm{Y}$, Yano $\mathrm{T}$, Asoh H, Yokoyama H, Yoshino I, Katsuda Y. Prognostic factors obtained by a pathologic examination in completely resected nonsmall-cell lung cancer. An analysis in each pathologic stage. J Thorac Cardiovasc Surg 1995; 110: 601-605.

24. Thomas PA, Pinatadosi S, for the Lung Cancer Study Group. Postoperative T1N0 non-small cell lung cancer: squamous versus non-squamous recurrences. J Thorac Cardiovasc Surg 1987; 94: 349-354.

25. Feld R, Rubinstein LV, Weisenberger TH. Sites of recurrences in resected stage I non-small-cell lung cancer: a guide for future studies. J Clin Oncol 1984; 2: $1352-1357$.

26. Mountain CF, Lukeman JM, Hammar SP. Lung cancer classification: the relationship of disease extent and cell type to survival in a clinical trials population. J Surg Oncol 1987; 35: 147-156.

27. Gail MH, Eagan RT, Feld R, et al. Prognostic factors in patients with resected stage I non-small cell lung cancer. A report from the Lung Cancer Study Group. Cancer 1984; 54: 1802-1813.

28. Kessler R, Gasser B, Massard G, et al. Blood-vessel invasion is a major prognostic factor in resected non-small cell lung cancer. Ann Thorac Surg 1996; 62: 1489-1493.

29. Macchiarini P, Fontanini G, Hardin JM, Pingitore R, Angletti CA. Most peripheral, node-negative, nonsmall cell lung cancers have low proliferative rates and no intratumoral and peritumoral blood and lymphatic vessel invasion. Rationale for treatment with wedge resection alone. J Thorac Cardiovasc Surg 1992; 104: 892-899.

30. Deslauriers J, Grégoire J. Surgical therapy of early non-small cell lung cancer. Chest 2000; 117: 104s-109s.

31. Jensik RJ, Faber LP, Milloy FG, Monson DO. Segmental resection for lung cancer. A fifteen-year experience. J Thorac Cardiovasc Surg 1973; 66: 563572.

32. Bennett WF, Abbey-Smith R. Segmental resection for bronchogenic carcinoma: a surgical alternative for the compromised patient. Ann Thorac Surg 1979; 27: 169172 . 
33. Hoffman TH, Ramsdell HT. Comparison of lobectomy and wedge resection for carcinoma of the lung. J Thorac Cardiovasc Surg 1980; 79: 211-217.

34. Kutschera W. Segment resection for lung cancer. Thorac Cardiovasc Surg 1984; 32: 102-104.

35. Errett LE, Wilson J, Chiu RC, Munro DD. Wedge resection as an alternative procedure for peripheral bronchogenic carcinoma in poor-risk patients. J Thorac Cardiovasc Surg 1985; 90: 656-661.

36. Miller JI, Hatcher CR. Limited resection of bronchogenic carcinoma in the patient with impairment of pulmonary function. Ann Thorac Surg 1987; 44: 340343.

37. Read RD, Yoder G, Schaeffer RC. Survival after conservative resection for T1N0M0 non-small cell lung cancer. Ann Thorac Surg 1990; 49: 391-400.

38. Pastorino $U$, Valente $\mathrm{M}$, Bedini $\mathrm{V}$, Infante $\mathrm{M}$, Tavecchio L, Ravasi G. Limited resection for stage I lung cancer. Eur J Surg Oncol 1991; 17: 42-46.

39. Kodama K, Doi O, Higashiyama M, Yokouchi H. Intentional limited resection for selected patients with T1N0M0 non-small cell lung cancer: a singleinstitution study. J Thorac Cardiovasc Surg 1997; 114: 347-353.

40. Warren WH, Faber LP. Segmentectomy versus lobectomy in patients with stage I pulmonary carcinoma: five-year survival and patterns of intrathoracic recurrence. J Thorac Cardiovasc Surg 1994; 107: 1087 1094.

41. Ginsberg RJ, Rubinstein LU, for the Lung Cancer Study Group. Randomized trial of lobectomy versus limited resection for T1N0M0 non-small cell lung cancer. Ann Thorac Surg 1995; 60: 615-623.

42. Miller JI. Limited resection of bronchogenic carcinoma in the patient with impaired pulmonary function. Ann Thorac Surg 1993; 56: 769-771.

43. Lewis RJ. The role of video-assisted thoracic surgery for carcinoma of the lung: wedge resection to lobectomy by simultaneous individual stapling. Ann Thorac Surg 1993; 56: 762-768.

44. Martini N, Burt ME, Bains MS, McCormack PM, Rusch VW, Ginsberg RJ. Survival after resection of stage II non-small cell lung cancer. Ann Thorac Surg 1992; 54: 460-466.

45. Yano T, Yokohama H, Inoue T, Asoh H, Tayama K, Ichinose Y. Surgical results and prognostic factors of pathologic N1 disease in non-small-cell carcinoma of the lung. Significance of N1 level: lobar or hilar nodes. J Thorac Cardiovasc Surg 1994; 107: 1398-1402.

46. The Lung Cancer Study Group. Effects of postoperative mediastinal radiation on completely resected stage II and stage III epidermoid cancer of the lung. $N$ Engl J Med 1986; 313: 1377-1381.

47. Feld R, Rubinstein L, Thomas PA, et al. Adjuvant chemotherapy with cyclophosphamide, doxorubicin, and cisplatin in patients with completely resected stage I non-small cell lung cancer. J Natl Cancer Inst 1993; 85: 299-306.

48. Figlin RA, Piantadosi S. A phase 3 randomized trial of immediate combination chemotherapy $v s$ delayed combination chemotherapy in patients with completely resected stage II and III non-small cell carcinoma of the lung. Chest 1994; 106: Suppl. 6, $310 \mathrm{~s}-312 \mathrm{~s}$.

49. Non-small Cell Lung Cancer Collaborative Group. Chemotherapy in non-small cell lung cancer: a metaanalysis using updated data on individual patients from 52 randomised clinical trials. $B M J$ 1995; 311 : 899-909.

50. Logan DM, Lochrin CA, Darling G, Eady A, Newman TE, Evans WK. Adjuvant radiotherapy and chemotherapy for stage II or IIIA non-small cell lung cancer after complete resection. Provincial Lung Cancer Disease Site Group. Cancer Prev Control 1997; 1: 366-378.

51. Pastorino U, Infante M, Maioli M, et al. Adjuvant treatment of stage I lung cancer with high-dose vitamin A. Am J Clin Oncol 1993; 11: 1216-1222.

52. Naruke T, Goya $T$, Tsuchiya R, Suemasu $K$. Prognosis and survival in resected lung carcinomas based on the new international staging system. J Thorac Cardiovasc Surg 1988; 96: 440-447.

53. Nakahashi H, Yasumoto K, Ishida T, et al. Results of surgical treatment of patients with T3 non-small cell lung cancer. Ann Thorac Surg 1988; 46: 178-181.

54. Luketich JD, Van Raendock DE, Ginsberg RJ. Extended resection for higher-stage non-small cell lung cancer. World J Surg 1993; 17: 719-728.

55. Facciolo F, Cardillo G, Lopergolo M, Pallone G, Sera F, Martelli M. Chest wall invasion in non-small cell lung carcinoma: a rationale for en bloc resection. J Thorac Cardiovasc Surg 2001; 121: 649-656.

56. Ratto GB, Piaconza G, Fiola C. Chest wall involvement by lung cancer: computed tomographic detection and results of operation. Ann Thorac Surg 1991; 51: 182-188.

57. Trastek VF, Pairolero PC, Piehler JM, et al. En bloc (non-chest wall) resection for bronchogenic carcinoma with parietal fixation. Factors affecting survival. J Thorac Cardiovasc Surg 1984; 87: 352-358.

58. McCaughan BC, Martini N, Bains MS, McCormack PM. Chest wall invasion in carcinoma of the lung. J Thorac Cardiovasc Surg 1985; 89: 836-841.

59. Magdeleinat $\mathrm{P}$, Alifano $\mathrm{M}$, Benbrahem $\mathrm{C}$, et al. Surgical treatment of lung cancer invading the chest wall: results and prognostic factors. Ann Thorac Surg 2001; 71: 1094-1099.

60. Patterson GA, Ilves R, Ginsberg RJ, Cooper JD, Todd TR, Pearson FG. The value of adjuvant radiotherapy in pulmonary and chest wall resection for bronchogenic carcinoma. Ann Thorac Surg 1982; 34: 692-697.

61. Piehler JM, Pairolero PC, Weiland LH, Offord KP, Payne WS, Bernatz PE. Bronchogenic carcinoma with chest wall invasion: factors affecting survival following en bloc resection. Ann Thorac Surg 1982; 34: 684 691.

62. Attar S, Krasna MJ, Sonett JR, et al. Superior sulcus (Pancoast) tumor: experience with 105 patients. Ann Thorac Surg 1998; 66: 193-198.

63. Pancoast HK. Superior pulmonary sulcus tumors. JAMA 1932; 99: 1391-1396.

64. Shaw RR, Paulson DL, Kee JL. Treatment of the superior sulcus tumor by irradiation followed by resection. Ann Surg 1961; 154: 29-40.

65. Hilaris BS, Martini N, Wong GY, Nori D. Treatment of superior sulcus tumor (Pancoast tumor). Surg Clin North Am 1987; 67: 965-977.

66. Van Raemdonck DE, Schneider A, Ginsberg RJ. Surgical treatment for higher stage non-small cell lung cancer. Ann Thorac Surg 1992; 54: 999-1013.

67. Gandhi S, Walsh GL, Komaki R, et al. A multidisciplinary surgical approach to superior sulcus 
tumors with vertebral invasion. Ann Thorac Surg 1999; 68: 1778-1785.

68. Dartevelle PH, Chapelier AR, Macchiarini P, et al. Anterior transcervical thoracic approach for radical resection of lung tumors invading the thoracic inlet. J Thorac Cardiovasc Surg 1993; 105: 1025-1034.

69. Grunenwald D, Spaggiari L. Transmanubrial osteomuscular approach for apical chest tumors. Ann Thorac Surg 1997; 63: 563-566.

70. Carrel T, Nachbur B, Bleher A. Is radiotherapy prior to surgical resection indicated for bronchogenic carcinoma with chest wall infiltration and for Pancoast tumors? Lung Cancer 1988; 4: A.80.

71. Tronc F, Grégoire J, Rouleau J, Deslauriers J. Longterm results of sleeve lobectomy for lung cancer. Eur J Cardiothorac Surg 2000; 17: 550-556.

72. Tedder M, Anstadt MP, Tedder SD, Lowe JE. Current morbidity, mortality, and survival after bronchoplastic procedures for malignancy. Ann Thorac Surg 1992; 54: 387-391.

73. Gaissert HA, Mathisen DJ, Moncure AC, Hilgenberg AD, Grillo HC, Wain JC. Survival and function after sleeve lobectomy for lung cancer. J Thorac Cardiovasc Surg 1996; 111: 948-953.

74. Van Schil PE, Brutel de la Rivière A, Knaepen PJ, et al. Long-term survival after bronchial sleeve resection: univariate and multivariate analyses. Ann Thorac Surg 1996; 61: 1087-1091.

75. Belli L, Meroni A, Rondinara G, Biati CA. Bronchoplastic procedures and pulmonary artery reconstruction in the treatment of bronchogenic cancer. $J$ Thorac Cardiovasc Surg 1985; 90: 167-171.

76. Maggi G, Casadio C, Pischedda F, Cianci R, Ruffini E, Filosso P. Bronchoplastic and angioplastic techniques in the treatment of bronchogenic carcinoma. Ann Thorac Surg 1993; 55: 1501-1507.

77. Rendina EA, Venuto F, De Giacomo T, et al. Sleeve resection and prosthetic reconstruction of the pulmonary artery for lung cancer. Ann Thorac Surg 1999; 68: 995-1002.

78. Rendina EA, Venuta F, De Giacomo T, Flaishman I, Fazi P, Ricci C. Safety and efficacy of bronchovascular reconstruction after induction chemotherapy for lung cancer. J Thorac Cardiovasc Surg 1997; 114: 830-837.

79. Roviaro G, Varoli F, Romanelli A, Vergani C, Maciocco M. Complications of tracheal sleeve pneumonectomy: personal experience and overview of the literature. J Thorac Cardiovasc Surg 2001; 121: 234 240.

80. Dartevelle PG, Macchiarini P, Chapelier A. Tracheal sleeve pneumonectomy. Ann Thorac Surg 1995; 60: 1854-1855.

81. Deslauriers J, Beaulieu M, McClish A. Tracheal sleeve pneumonectomy. In: Shields TW, ed. General Thoracic Surgery. 3rd Edn. Philadelphia, PA, Lea and Febiger, 1989; pp. 382-387.

82. Demeester TR, Albertucci M, Dawson PJ, Montner SM. Management of tumor adherent to the vertebral column. J Thorac Cardiovasc Surg 1989; 97: 373-378.

83. Grunenwald D, Mazel C, Girard P, Berthiot G, Dromer C, Baldeyrou P. Total vertebrectomy for en bloc resection of lung cancer invading the spine. Ann Thorac Surg 1996; 61: 723-726.

84. Martini N, Flehinger BJ, Zaman MB, Beattie EJ.
Results of resection of non-oat cell carcinoma of the lung with mediastinal lymph node metastasis. Ann Surg 1983; 198: 386-397.

85. Watanabe Y, Hayashi Y, Shimizu J, Oda M, Iwa T. Mediastinal nodal involvement and the prognosis of non-small cell lung cancer. Chest 1991; 100: 422-428.

86. Patterson GA, Piazza D, Pearson FG, et al. Significance of metastatic disease in subaortic lymph nodes. Ann Thorac Surg 1987; 43: 155-159.

87. Pearson FG, Delarue NC, Ilves R, Todd TR, Cooper JD. Significance of positive superior mediastinal nodes identified at mediastinoscopy in patients with resectable cancer of the lung. $J$ Thorac Cardiovasc Surg 1982; 83: 1-11.

88. Daly BD, Mueller JD, Faling LJ, et al. N2 lung cancer: outcome in patients with false-negative computed tomographic scans of the chest. $J$ Thorac Cardiovasc Surg 1993; 105: 904-911.

89. Goldstraw P, Mannam GC, Kaplan DK, Michail P. Surgical management of non-small cell lung cancer with ipsilateral mediastinal node metastasis (N2 disease). J Thorac Cardiovasc Surg 1994; 107: 19-28.

90. Vansteenkiste JF, De Leyn PR, Deneffe GJ, et al. Survival and prognostic factors in resected N2 nonsmall cell lung cancer: a study of 140 cases. Leuven Lung Cancer Group. Ann Thorac Surg 1997; 63: 14411450 .

91. Watanabe Y, Shimizu J, Oda M, et al. Improved survival in left non-small-cell N2 lung cancer after more extensive operative procedure. Thorac Cardiovasc Surg 1991; 392: 89-94.

92. Naruke T, Goya T, Tsuchiya R, Suemasu K. The importance of surgery in non-small cell carcinoma of lung with mediastinal lymph node metastasis. Ann Thorac Surg 1988; 46: 603-610.

93. Kirsh MM, Sloan H. Mediastinal metastases in bronchogenic carcinoma, influence of postoperative irradiation, cell type, and location. Ann Thorac Surg 1982; 333: 459-463.

94. The Lung Cancer Study Group. Effects of postoperative mediastinal radiation on completely resected stage II and III epidermoid cancer of the lung. $N$ Engl J Med 1986; 315: 1377-1381.

95. Martini N, Kris MG, Flehinger BJ, et al. Preoperative chemotherapy of stage III-a (N2) non-small cell lung cancer: the Sloan-Kettering experience with 136 patients. Ann Thorac Surg 1993; 55: 1365-1374.

96. Rosell R, Gomez-Codina J, Camps C, et al. A randomized trial comparing preoperative chemotherapy plus surgery with surgery alone in patients with non-small cell lung cancer. N Engl J Med 1994; 330: $153-158$

97. Roth J, Fossella F, Komaki R, et al. A randomized trial comparing perioperative chemotherapy and surgery with surgery alone in resectable stage IIIA non-small cell lung cancer. J Natl Cancer Inst 1994; 86: 673-680.

98. Gandara DR, Leigh B, Vallières E, Albain KS. Preoperative chemotherapy in stage III non-small cell lung cancer: long-term outcome. Lung Cancer 1999; 26: 3-6.

99. Deslauriers J. Should screening for lung cancer be revisited? J Thorac Cardiovasc Surg 2001; 121: 10311032. 